\title{
Yoga Research a Scientometric Assessment of Global Publications Output during 2007-16
}

\author{
BM Gupta', KK Mueen Ahmed², SM Dhawan³ ${ }^{3}$ Ritu Gupta ${ }^{4}$
}

\section{BM Gupta ${ }^{1}$, KK Mueen Ahmed ${ }^{2}$, SM Dhawan $^{3}$, Ritu Gupta ${ }^{4}$}

11173 Sector 15, Panchkula 134113 Haryana, INDIA.bmgupta1@gmail.com 2Phcog.Net and SciBiolMed.Org, Bengaluru, Karnataka, INDIA. ${ }^{3}$ Formerly CSIR-NPL, New Delhi, 114 Dayanand Vihar, Delhi, INDIA. ${ }^{4} 1 \mathrm{~K} / \mathrm{A}$ Arjun Nagar, Safdarjang Enclave, New Delhi, INDIA.

\section{Correspondence}

Ritu Gupta

1K/A Arjun Nagar, Safdarjang Enclave, New Delhi 110029, INDIA.

E-mail: ritu7648@gmail.com

History

- Submission Date: 05-06-2017;

- Review completed: 22-08-2017

- Accepted Date: 03-12-2017

DOI : 10.5530/pj.2018.3.65

Article Available online

http://www.phcogj.com/v10/i3

\section{Copyright}

(C) 2018 Phcog.Net. This is an openaccess article distributed under the terms of the Creative Commons Attribution 4.0 International license.

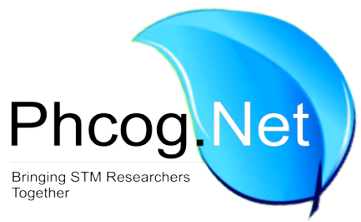

\begin{abstract}
The paper examines 3966 global publications on yoga research, as covered in Scopus database during 2007-16. The global output on yoga research output registered $7.79 \%$ growth, and citation impact averaging to 10.44 citations per paper. The top 10 most productive countries in yoga research individually contributed global share from $1.31 \%$ to $38.35 \%$, with largest global publication share coming from USA $(38.35 \%)$, followed by India $(19.29 \%)$, U.K. $(6.61 \%)$, Canada (5.09\%), etc. Together, the 10 most productive countries accounted for $83.74 \%$ and $96.67 \%$ global publication and global citation share during 2007-16. Five of top 10 countries scored relative citation index above the world average i.e. more than 1: Canada (1.81), USA (1.37), Germany (1.34), U.K. (1.31) and Italy (1.12) during 2007-16. The international collaborative publications share of top 10 most productive countries in yoga research varied from $12.68 \%$ to $42.59 \%$ during 2007-16. Medicine, among subjects, contributed the largest publication share $(78.67 \%)$, followed by 9 other subjects with global share between $5.09 \%$ and $9.56 \%$. The top 25 most productive organizations and authors together contributed $21.63 \%$ and $16.84 \%$ respectively as their global publication share and $35.37 \%$ and $25.10 \%$ respectively as their global citation share during 2007-16. Among the total journal output of 3719 papers, the top 15 journals contributed $21.22 \%$ share to the global journal output during 2007-16. Of the global yoga research output, the top 44 publications registered high citations from 101 to 1092 and they together cumulated 8304 citations, averaging to 188.72 citations per paper. These 44 highly cited papers were published in 35 journals, 5 papers were published in Cochrane database of systematic reviews (Online), 2 papers each in Annals of Internal Medicine, Integrative Cancer Therapies, Journal of Alternative and Complementary Medicine and Pain and 1 paper each in other journals.
\end{abstract}

Key words: Yoga research, Medical diseases, Global publications, Scientometrics, Bibliometrics.

\section{INTRODUCTION}

Yoga is a healing system practised for over 5,000 years combining breathing exercises, physical postures, and meditation for relaxation, flexibility, range of motion and strength, and restoring balance in the nervous system. ${ }^{1}$ Yoga has positive healing effects on a broad spectrum of health domains, physiologic as well as psychological well-being. ${ }^{2}$ As a holistic application, an adjuvant therapy in clinical practice, yoga provides health benefits beyond traditional treatment alone. Yoga practices unify the mind and body through coordinated breathing (pranayama), movement (asana) and meditation (dhyana). Yoga reduces stress and anxiety, controls aggravating effects of stress on cardiovascular health, mental health, chronic pain, and sleep disorders in human being. ${ }^{3,4}$ Yoga has emerged as a philosophical or spiritual discipline of theory and practice, bringing relief to human beings, alleviating their sufferings from disease, ${ }^{5}$ from depression, anxiety $)^{6,7,8}$ and from biological, psychological and social disruptions caused by stress. ${ }^{9,10,11}$

Scientists and doctors from institutions across the world are engaged in research pursuits to make yoga beneficial and useful to mankind, and to make sure that yoga interventions are effective in all the dimensions of health - physical, mental, social, and spiritual. The present study is a bibliometric study seeking to map yoga research across the world, identify top countries dominating yoga research, top productive institutions, and top authors contributing to yoga research. Such a study will provide comparative performance of countries, institutions and authors on yoga research as well as provide the stakeholders an insight into the current directions in yoga research.

\section{Literature Review}

Only few quantitatively studies are available on yoga research. Among such studies, Khalsa ${ }^{11}$ indicate that although yoga is historically a spiritual discipline, it has been used clinically as a therapeutic intervention. A bibliometric analysis on the biomedical journal literature involving research on the clinical application of yoga has revealed an increase in publication frequency over the past 3 decades with a substantial and growing use of randomized 
controlled trials. Types of medical conditions have included psychopathological (e.g. depression, anxiety), cardiovascular (e.g. hypertension, heart disease), respiratory (e.g. asthma), diabetes and a variety of others. Jeter, Slutsky, Singh and Khalsa ${ }^{12}$ conducted a bibliometric analysis on publications for yoga therapy research in clinical populations, using major electronic databases during 1967-2013. A total of 486 articles were analysed which met the inclusion criteria and were published in 217 different peer-reviewed journals from 29 different countries on 28,080 study participants. Overall, $45 \%$ of the studies published were randomized controlled trials, $18 \%$ were controlled studies, and $37 \%$ were uncontrolled studies. Most publications originated from India, followed by the United States and Canada. The top three disorders addressed by yoga interventions were mental health, cardiovascular disease, and respiratory disease. Field ${ }^{13}$ reviewed empirical studies and meta-analysis publications on yoga from the last few years. The review includes demographics/prevalence of yoga as a practice, bibliometric analyses of the yoga publications and the use of yoga for physical fitness and cognitive function. Most of the studies reviewed here involve yoga effects on psychiatric and medical conditions. These include pregnancy, prenatal and postpartum depression; stress, PTSD, anxiety, and obesity; cardiovascular conditions including hypertension; pain syndromes including arthritis, headaches and low back pain; autoimmune conditions including asthma, type II diabetes and multiple sclerosis; immune conditions including HIV and breast cancer; and aging problems including balance, osteoporosis and Parkinson's. Cramer, Lauche and Dobos ${ }^{14}$ investigated a growing number of randomized controlled trials (RCTs) for the therapeutic value of yoga interventions, with a view to provide a comprehensive review of the characteristics of the totality of available randomized yoga trials published during 1975-2014. A total of 366 papers were included, reporting 312 RCTs from 23 different countries with 22,548 participants. The median study sample size was 59 . Two hundred sixty-four RCTs (84.6\%) were conducted with adults, 105 (33.7\%) with older adults and 31 (9.9\%) with children. Eighty-four RCTs (26.9\%) were conducted with healthy participants. Other trials enrolled patients with one of 63 varied medical conditions; the most common being breast cancer (17 RCTs, 5.4\%), depression (14 RCTs, $4.5 \%$ ), asthma (14 RCTs, 4.5\%) and type 2 diabetes mellitus (13 RCTs, 4.2\%). Whilst 119 RCTs (38.1\%) did not define the style of yoga used, 35 RCTs (11.2\%) used Hatha yoga and 30 RCTs (9.6\%) yoga breathing. The remaining 128 RCTs (41.0\%) used 46 varied yoga styles, with a median intervention length of 9 weeks (range 1 day to 1 year; interquartile range $=5,12$ ). Two hundred and forty-four RCTs (78.2\%) used yoga postures, 232 RCTs (74.4\%) used breath control, 153 RCTs (49.0\%) used meditation and 32 RCTs (10.3\%) used philosophy lectures. One hundred and seventy-four RCTs (55.6\%) compared yoga with no specific treatment; 21 varied control interventions were used in the remaining RCTs.

\section{OBJECTIVES}

The main objectives of this study are to study the performance of global yoga research with reference to its interventions in medical diseases based on bibliometric analysis of publications output covered in Scopus database during 2007-16. In particular, the study focuses on the following objectives: (i) To study the growth of world research output in yoga research and its citation impact; (ii) To study the international collaboration share of top 10 most productive countries; (iii) To study the global research output by broad subject areas and the dynamics of its growth and decline; (iv) To study the trends in yoga interventions in medical diseases by identifying significant keywords; (v) To study the publication productivity and citation impact of top 25 most productive organizations and authors; (vi) To study the modes of communication in research and (vii) to study the characteristics of top 44 highly cited papers.

\section{METHODOLOGY}

Traditionally yoga is a combination of asana, pranayama, and meditation. Yoga is largely based on Patanjali or Hatha yoga, and it is also an umbrella term for the many newly formed styles since the adoption of yoga in the West.

The study retrieved and downloaded 10-year publication data of the world output in yoga research from the Scopus database (http://www. scopus.com) covering the period 2007-16. Keywords, such as "yoga" or "yoga therapy" or "pranayama" or "asana" were incorporated in the search string and qualified these keywords with "keyword tag" and "Source Title tag", and in addition incorporated in this search string the period '2007-16' within "date range tag". Finally this search string was applied for searching global publication data on global ypga research. The search string was subsequently refined by "subject area tag", "country tag", "source title tag", "journal title name" and "affiliation tag", to get data/information on the distribution of publications output by subject, collaborating countries, author-wise, organization-wise and journalwise, etc. For citation data, citations to publications were also collected from date of publication till 29 January 2017.

(KEY(yoga or yoga therapy or pranayama or asana) OR TITLE(yoga or yoga therapy or pranayama or asana)) AND PUBYEAR $>2006$ AND PUBYEAR $<2017$

(((KEY)(yoga or yoga therapy or pranayama or asana) OR TITLE(yoga or yoga therapy or pranayama or asana)) AND PUBYEAR > 2006 AND PUBYEAR < 2017) and (TITLE-ABS-KEY(depression) AND PUBYEAR > 2006 AND PUBYEAR < 2017))

\section{ANALYSIS}

\section{Publications Analysis}

The world output in the field of yoga research cumulated to a total of 3966 publications in 10 years during 2007-16. The global research output on yoga topics registered $7.79 \%$ growth, with its annual output growing from 244 in the year 2007 to 437 publications in the year 2016. Even at macro level, the yoga research output registered $74.76 \%$ quinquennial growth, up from 1445 during 2007-11 to 2521 publications in the succeeding five-year period 2012-16.

Of the total global publications output, $72.57 \%$ (2878) appeared as conference papers, $13.51 \%$ (536) as articles, 5.22\% (207) as reviews, $3.88 \%$ (154) articles in press, $1.79 \%$ (71) as book chapters and the rest as conference reviews, editorials, short surveys, notes, letters and books. The citation impact of global publications on yoga research averaged to 10.44 citations per publication (CPP) during 2007-16; Comparative citation performance evaluation reveals that five-yearly citation impact averaged to a high of $18.41 \mathrm{CPP}$ for the period 2007-11, but declined to 5.87 CPP in the succeeding five-year period 2012-16 (Table 1).

\section{Top 10 Most Productive Countries in Yoga Research}

Yoga research is though spread across as many as 77 countries in the world, but the geographical distribution of research productivity in the yoga field is highly skewed, confined mainly to top 10 countries. These 10 countries together account for $83.74 \%$ world publication share and $96.67 \%$ world citation share during 2007-16. Macro level global publication performance evaluation reveals that cumulative five-yearly global publication share jumped moderately up from $79.38 \%$ during 2007-11 to $86.24 \%$ during succeeding 5-year period 2012-16. Global publication share of each of top 10 countries varied widely -- $1.31 \%$ to $38.35 \%$-- (55 to 1521 publications) with the USA accounting for the highest publication share (38.35\%), followed by India (19.29\% share), U.K. (6.61\%), Canada (5.09\% share), Australia (4.54\% share), Germany (4.39\%), Brazil (1.41\%), Italy (1.39\%), South Korea (1.36\%) and China 
(1.31\%) during 2007-17 (Table 2). Only two countries, USA and UK, witnessed jump in their cumulative five-yearly global publication share by $0.43 \%$ and $0.54 \%$. Whereas the other eight countries - India, Germany, South Korea, Australia, China, Italy, Brazil, and Canada - witnessed decline in their cumulative five-yearly global publication share by $0.002 \%$ to $1.34 \%$ during the period from $2007-11$ to $2012-16$. As stated earlier the geographical distribution of publications across 77 countries is highly skewed with 45 accounting 1-10 papers each, 22 countries for 11-50 papers each, 4 countries for 51-100 papers each, 5 countries for 174 to 765 papers each and 1 country for 1521 papers. Five of top 10 countries - Canada (1.81), USA (1.37), Germany (1.34), U.K. (1.31) and Italy (1.12) -- scored relative citation index above the world average of 1 during 2007-16 (Table 2).

Table 1: Global Publication Output in Yoga Research, 2007-16.

\begin{tabular}{cccc}
\hline Publication & & World & \\
\cline { 2 - 4 } Period & TP & TC & CPP \\
\hline 2007 & 244 & 7726 & 31.66 \\
2008 & 216 & 4625 & 21.41 \\
2009 & 266 & 4665 & 17.54 \\
2010 & 327 & 4365 & 13.35 \\
2011 & 392 & 5225 & 13.33 \\
2012 & 462 & 5381 & 11.65 \\
2013 & 541 & 4694 & 8.68 \\
2014 & 547 & 2895 & 5.29 \\
2015 & 534 & 1489 & 2.79 \\
2016 & 437 & 331 & 0.76 \\
$2007-11$ & 1445 & 26606 & 18.41 \\
$2012-16$ & 2521 & 14790 & 5.87 \\
$2007-16$ & 3966 & 41396 & 10.44 \\
\hline
\end{tabular}

TP=Total Papers; $\mathrm{TC}=$ Total Citations; $\mathrm{CPP}=$ Citations Per Paper

\section{International Collaboration}

The international collaborative share of top 10 countries in yoga research in their respective national output varied from $12.68 \%$ to $42.59 \%$, with highest share coming from South Korea $(42.59 \%)$, followed by China (38.46\%), Germany (37.93\%), U.K. (35.88\%), Italy (34.55\%), Canada (32.67\%), Australia (29.44\%), Brazil (17.86\%), USA (12.69\%) and India (12.68\%) during 2007-16.

\section{Subject-Wise Distribution of Research Output}

The yoga research output published globally during 2007-16 is distributed across nine sub-fields (as identified in Scopus database classification), with medicine accounting for the highest publications share $(78.67 \%)$, followed by psychology (9.56\%), biochemistry, genetics and molecular biology $(9.53 \%)$, health profession $(8.90 \%)$, nursing $(8.63 \%)$, social sciences $(7.56 \%)$, arts and humanities (6.98\%), pharmacology, toxicology and pharmaceutics (5.85\%) and neurosciences (5.09\%) during 2007-16.

The yoga-related research activity across major disciplines was compared on activity index measure. The world average activity index of a given subject is taken as 100 . The activity index computes changes in research activity in a discipline over time 2007-11 to 2012-16 compared to the world average activity of the discipline, the index value of which is taken as 100 . The study found rise over time in research activity in medicine (from 99.84 to 100.09), social sciences (from 86.36 to 107.82) and neurosciences (from 92.39 to 104.36). Besides, the study also found decline in research activity over time in health profession (from 107.30 to 95.82 ) and nursing (from 121.63 to 87.60 ) during the period from 2007-11 to 2012-16. Psychology, compared to other subjects, registered the highest impact of 11.83 citations per paper, followed by biochemistry, genetics and molecular biology (11.79), medicine (11.47), nursing (10.29), health profession (7.89), pharmacology, toxicology and pharmaceutics (7.16), arts and humanities (4.35) and social sciences (3.55) during 2007-16 (Table 3).

\section{Significant Keywords}

More than $90 \%$ of the yoga research publications are devoted to yoga interventions in medical and allied sciences. A large number of significant keywords (under broad disease groups) which seek to highlight research

Table 2: Global Publication Share of Top 10 Most Productive Countries in Yoga Research during 2007-16.

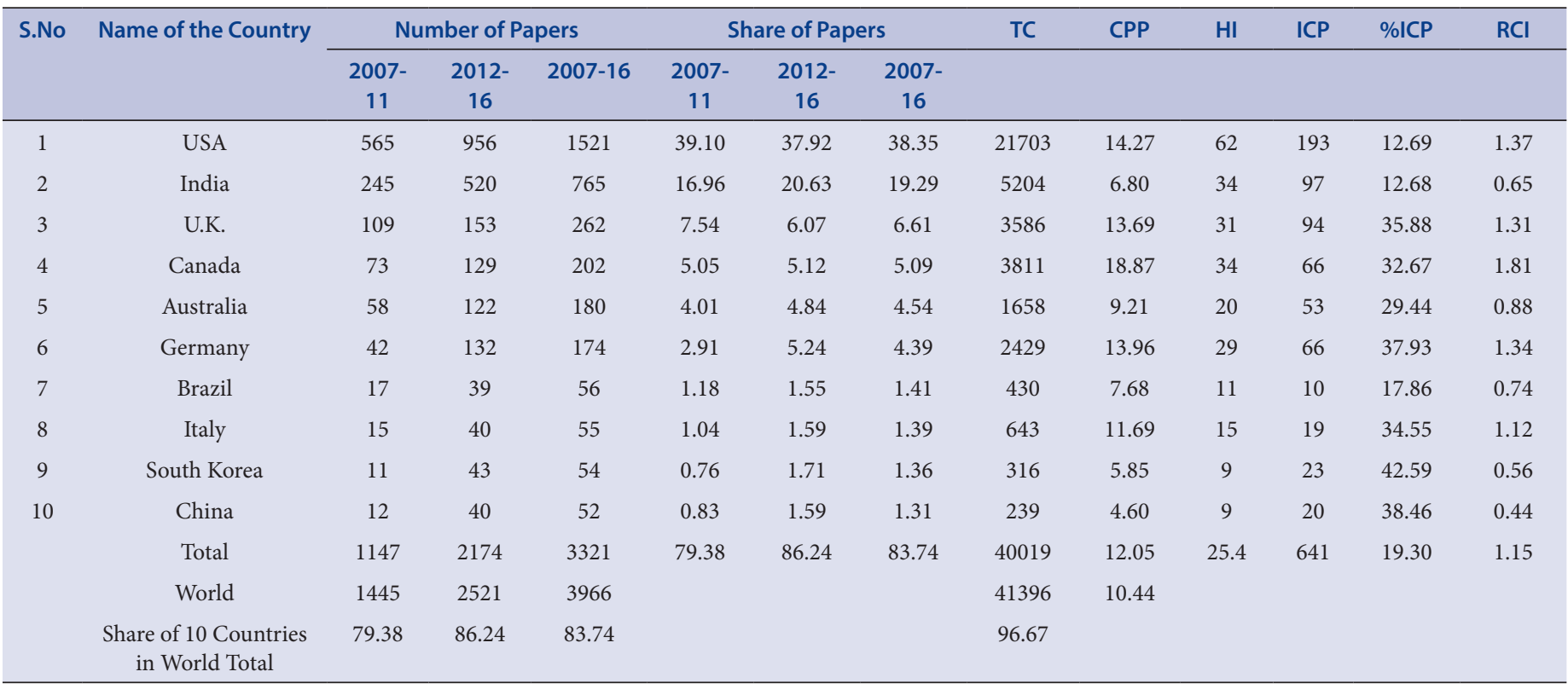

TP=Total Papers; TC=Total Citations; CPP=Citations Per Paper; HI=h-index; ICP=International Collaborative Papers; RCI=Relative Citation Index 
Gupta et al.: Yoga Research a Scientometric Assessment of Global Publications Output during 2007-16

Table 3: Subject-Wise Breakup of Global Publications in Yoga Research during 2007-16.

\begin{tabular}{|c|c|c|c|c|c|c|c|c|}
\hline \multirow[t]{2}{*}{ Subject* } & \multicolumn{3}{|c|}{ Number of Papers (TP) } & \multicolumn{2}{|c|}{ Activity Index } & \multirow{2}{*}{$\frac{\text { TC }}{2007-16}$} & \multirow{2}{*}{$\begin{array}{c}\text { CPP } \\
2007-16\end{array}$} & \multirow{2}{*}{$\begin{array}{c}\% \text { TP } \\
2007-16\end{array}$} \\
\hline & 2007-11 & 2012-16 & 2007-16 & 2007-11 & 2012-16 & & & \\
\hline Medicine & 1135 & 1985 & 3120 & 99.84 & 100.09 & 35784 & 11.47 & 78.67 \\
\hline Psychology & 119 & 260 & 379 & 86.18 & 107.92 & 4482 & 11.83 & 9.56 \\
\hline $\begin{array}{l}\text { Biochemistry, Genetics and } \\
\text { Molecular Biology }\end{array}$ & 122 & 256 & 378 & 88.58 & 106.54 & 4456 & 11.79 & 9.53 \\
\hline Health Profession & 138 & 215 & 353 & 107.30 & 95.82 & 2785 & 7.89 & 8.90 \\
\hline Nursing & 152 & 191 & 343 & 121.63 & 87.60 & 3531 & 10.29 & 8.65 \\
\hline Social Sciences & 87 & 213 & 300 & 79.59 & 111.70 & 1064 & 3.55 & 7.56 \\
\hline Arts and Humanities & 85 & 192 & 277 & 84.22 & 109.04 & 1206 & 4.35 & 6.98 \\
\hline $\begin{array}{c}\text { Pharmacology, Toxicology and } \\
\text { Pharmaceutics }\end{array}$ & 73 & 159 & 232 & 86.36 & 107.82 & 1662 & 7.16 & 5.85 \\
\hline Neurosciences & 68 & 134 & 202 & 92.39 & 104.36 & 3502 & 17.34 & 5.09 \\
\hline World Output & 1445 & 2521 & 3966 & 100.00 & 100.00 & & & \\
\hline
\end{tabular}

There is overlapping of literature covered under various subjects TP=Total Papers; TC=Total Citations; CPP=Citations Per Paper

trends in yoga interventions, were identified from the literature and are listed in the decreasing order of the frequency of their occurrence during 2007-16 (Table 4). In terms of individual diseases, the largest yoga interventions were on depression (312 papers), stress (369 papers), anxiety (186 papers), breast cancer (138), neurologic disease (133), obesity (127), pain (125), anxiety disorders (119), chronic pain (104), stress (91), stress management (89), psychological stress (87), neoplasm (84), low back pain (79), insomnia (78), mental health (78), osteopathic medicine (77), mental stress (73), breast neoplasms (70), asthma (62), fibromyalgia (58), cardiovascular disease (54), diabetes mellitus (54), hypertension (53), blood pressure (48), rheumatoid arthritis (44), schizophrenia (43), pregnancy (43), post-traumatic stress (42), eating disorders (42), menopause syndrome (41), mental stress (40), major depression (40), non-Insulin Dependent Diabetes Mellitus (40), mental disease (39), headache (39), knee osteoarthritis (37), menopause (36), neck pain (36), occupational therapy (34), backache (31), gastrointestinal symptoms (31), etc.

\section{Profile of Top 25 Most Productive Global Organizations.}

In global yoga research, the productivity of 25 most productive global organizations varied from 21 to 58 publications and together they contributed $21.63 \%$ (858) publication share and 35.37\% (14640) citation share to its cumulative publications output during 2007-16. The scientometric profile of these 25 organizations is presented in Table 5. Nine of these organizations registered publications output greater than the group average of 34.32: Veterans Affairs Medical Center, USA (58 papers), University of Washington, Seattle, USA (55 papers), National Institute of Mental Health and Neurosciences, Bangalore, India (51 papers), University of California, Los Angles, USA (50 papers), University of Duisburg-Essen, Germany (49 papers), Harvard Medical School, USA (41 papers), Brigham and Women's Hospital, Boston, USA (40 papers), University of California, San Francisco, USA(38 papers) and University of Toronto, Canada (36 papers) during 2007-16.

Nine organizations registered citation impact above the group average of 17.06 citations per publication during 2007-16: University of British Columbia, Canada (36.43), Boston University School of Medicine, USA (33.28), University of California, San Francisco, USA (30.53) Harvard Medical School, USA (28.07), University of Calgary, Canada (25.40), Massachusetts General Hospital, USA (19.74), University of California, Los Angles, USA (18.76), University of Texas M.D. Anderson Cancer
Center, USA (18.62) and University of Pennsylvania, USA (17.84) during 2007-16.

Fourteen organizations registered h-index above the group average of 12.68: University of California, San Francisco, USA, Harvard Medical School, USA and Veterans Affairs Medical Center, USA (18 each), Veterans Affairs Medical Center, USA, University of Duisburg-Essen, Germany, Brigham and Women's Hospital, Boston, USA and University of Washington, Seattle, USA (17 each), Group Health Research Institute, Seattle, USA (16), Boston University School of Medicine, USA, University of Calgary, Canada, Massachusetts General Hospital, USA, University of Sydney, Australia, University of Toronto, Canada and National Institute of Mental Health and Neurosciences, Bangalore, India (13 each) during 2007-16.

Thirteen organizations contributed international collaborative publications share above the group average of $22.14 \%$ : University of Exeter, U.K. (50.0\%), University of Technology, Sydney, Australia (48.15\%), University of Calgary, Canada (40.0\%), University of Toronto, Canada (38.89\%), Massachusetts General Hospital, USA (37.04\%), University of DuisburgEssen, Germany (36.73\%), University of British Columbia, Canada and University of Texas M.D. Anderson Cancer Center, USA (28.57\% each), Brigham and Women's Hospital, Boston, USA (27.5\%),University of California, San Francisco, USA (26.32\%) and University of California, San Diego, USA (25.81\%) during 2007-16.

Nine organizations registered the relative citation index above the group average (1.63) of all organizations: University of British Columbia, Canada (3.49), Boston University School of Medicine, USA (3.19), University of California, San Francisco, USA (2.92), Harvard Medical School, USA (2.69), University of Calgary, Canada (2.43), Massachusetts General Hospital, USA (1.89), University of California, Los Angles, USA (1.80), University of Texas M.D. Anderson Cancer Center, USA (1.78) and University of Pennsylvania, USA (1.71) during 2007-16.

\section{Profile of Top 25 Most Productive Authors.}

In the field of global yoga research, the research productivity of top 25 most productive authors varied from 13 to 69 publications. Together they contributed $16.84 \%$ (668) global publication share and $25.10 \%$ (10389) citation share during 2007-16. The scientometric profile of these 25 authors is presented in Table 6. 
Table 4: List of Significant Keywords in Literature on Yoga Interventions in Medical Diseases during 2007-16.

\begin{tabular}{|c|c|}
\hline Disease (Number of Papers) & Keywords (Frequency) \\
\hline Mental Health (203) & Mental health (78), Mental stress (40), Mental disease (39), Mental disorders (19) \\
\hline Depression (377) & Depression (312), Major depression (40) \\
\hline Fatigue (170) & Fatigue (170) \\
\hline Anxiety (313) & Anxiety (186), Anxiety disorders (119), Hospital anxiety and depression scale(16), Generalized anxiety disorder (15) \\
\hline Stress (369) & $\begin{array}{l}\text { Stress (91), Stress management (89), Psychological stress (87), Mental stress (73), Post-traumatic stress (42), Distress syndrome } \\
\text { (27), }\end{array}$ \\
\hline Physical Fitness (47) & Physical Fitness (23) \\
\hline Pulmonary disease & Chronic obstructive pulmonary disease (12), Chronic obstructive lung disease (10), Lung function (8) \\
\hline $\begin{array}{l}\text { Blood Pressure and } \\
\text { Hypertension (109) }\end{array}$ & Hypertension (53), Blood pressure (48) \\
\hline Metabolic Endocrine & Metabolic Endocrine (4), Glucose regulation (4), Menopause syndrome (41), Menopause (36), Vitamin deficiency (10) \\
\hline Musculoskeletal disease (80) & Musculoskeletal disease (25), Musculoskeletal pain (17), Musculoskeletal manipulations (10) \\
\hline Arthritis (59) & Rheumatoid arthritis (44), Knee Osteoarthritis (37), Osteoarthritis (23) Hip Osteoarthritis (10) \\
\hline Osteoporosis (165) & Osteopathic medicine (77), Osteoporosis (20) \\
\hline Fibromyalgia syndrome (61) & Fibromyalgia (58) \\
\hline Rheumatic diseases & Rheumatic arthritis (44), Rheumatic diseases (13),), Rheumatology (3) \\
\hline Pain (389) & $\begin{array}{l}\text { Pain (125), Chronic pain (104), Low back pain (79), Pain assessment (68), Headache (39), Pain management (38), Backache } \\
\text { (31), Abdominal pain (25), Neuropathic pain (25), Cancer pain (24), Migraine (23), Knee Pain (20), Carpal tunnel syndrome } \\
\text { (14) }\end{array}$ \\
\hline Cancer (343) & $\begin{array}{c}\text { Breast cancer (138), neoplasm (84)Breast neoplasms (70), Cancer therapy (67), Cancer survivor (61), Cancer (57), Cancer } \\
\text { radiography (53), Cancer chemography (51), Multimodality cancer therapy (38), Oncology (37), Cancer fatigue (29), Prostate } \\
\text { cancer (27), Cancer pain (24), Cancer hormone therapy (23), Cancer surgery (21), Cancer staging (19), medical oncology (17), } \\
\text { Head and Neck cancer (14), Female Genital neoplasm (8) }\end{array}$ \\
\hline Heart Diseases (222) & $\begin{array}{l}\text { Cardiovascular disease (54), Heart rate (43), Cardiovascular risk (26), Heart rate variability (23), Heart failure (19), Heart } \\
\text { infarction (16), Cerebrovascular disease (3), Ischemic heart disease (3) }\end{array}$ \\
\hline Respiratory diseases $(100)$ & Asthma (62), \\
\hline Sleep disorders $(87)$ & Insomnia (78), Sleep disorder (24), Sleep ignition and maintainence disorder (16) \\
\hline Neuro disorders & $\begin{array}{l}\text { Neurologic disease (133), Schizophrenia (43), Epilepsy (27), Parkinson disease (27), Stroke (27), Dementia (29), bipolar } \\
\text { disorder (20),Panic (15) Learning Disorders (8), Cerebral palsy (3), }\end{array}$ \\
\hline HIV/AIDS & HIV Infection (19), AIDS (5), HIV/AIDS (3) \\
\hline Diabetes (103) & $\begin{array}{c}\text { Diabetes Mellitus (54), Non-Insulin Dependent Diabetes Mellitus (40), Diabetes Mellitus, Type } 2 \text { (13), Insulin Dependent } \\
\text { Diabetes Mellitus (7) }\end{array}$ \\
\hline Gastro disease (68) & Gastrointestinal symptoms (31), Gastroesophageal reflux (11), Gastrointestinal disease (16) \\
\hline Bowel Syndrome (24) & Irritable bowel syndrome (11) \\
\hline Pregnancy (53) & Pregnancy (43), Pregnancy complications (13), Premature labor (7) \\
\hline Obesity (127) & Obesity (127), Body mass (22), Weight reduction (18), Body Weight $\left.{ }^{\star} 14\right)$, Overweight (7) \\
\hline \multicolumn{2}{|l|}{ Autoimmune diseases (9) } \\
\hline Allergy (22) & Allergy (12), Sinusitis (4), Rhinitis (3) \\
\hline Kidney & Kidney failure (9), Kidney disease (8) \\
\hline Ortho & Neck pain (36), Knee (13), Hand Grip (12), Knee Joint (9),Leg pain (10), Leg (6) \\
\hline Malaria & Malaria (7) \\
\hline Fertility & Male Fertility (4) \\
\hline Occupational diseases & Occupational therapy (34), Occupational health (19)Occupational disease (7) \\
\hline Eating disorders & Eating disorders (42) \\
\hline
\end{tabular}


Table 5: Scientometric Profile of Top 25 Most Productive Global Organizations in Global Yoga Research during 2007-16.

\begin{tabular}{|c|c|c|c|c|c|c|c|}
\hline Name of the Organization & TP & TC & CPP & HI & ICP & $\% \mathrm{ICP}$ & $\mathrm{RCl}$ \\
\hline Veterns Affairs Medical Center, USA & 58 & 951 & 16.40 & 18 & 7 & 12.07 & 1.57 \\
\hline University of Washington, Seattle, USA & 55 & 770 & 14.00 & 17 & 4 & 7.27 & 1.34 \\
\hline National Institute of Mental Health and Neurosciences, Bangalore, India & 51 & 566 & 11.10 & 13 & 5 & 9.80 & 1.06 \\
\hline University of California, Los Angles, USA & 50 & 938 & 18.76 & 17 & 5 & 10.00 & 1.80 \\
\hline University of Duisburg-Essen, Germany & 49 & 831 & 16.96 & 17 & 18 & 36.73 & 1.62 \\
\hline Harvard Medical School, USA & 41 & 1151 & 28.07 & 18 & 10 & 24.39 & 2.69 \\
\hline Brigham and Women's Hospital, Boston, USA & 40 & 622 & 15.55 & 17 & 11 & 27.50 & 1.49 \\
\hline University of California, San Francisco, USA & 38 & 1160 & 30.53 & 18 & 10 & 26.32 & 2.92 \\
\hline University of Toronto, Canada & 36 & 532 & 14.78 & 13 & 14 & 38.89 & 1.42 \\
\hline All India Institute of Medical Sciences, India & 33 & 246 & 7.45 & 9 & 2 & 6.06 & 0.71 \\
\hline Group Health Research Institute, Seattle, USA & 33 & 528 & 16.00 & 16 & 6 & 18.18 & 1.53 \\
\hline University of Sydney, Australia & 32 & 522 & 16.31 & 13 & 8 & 25.00 & 1.56 \\
\hline University of Pennsylvania, USA & 31 & 553 & 17.84 & 12 & 3 & 9.68 & 1.71 \\
\hline University of California, San Diego, USA & 31 & 354 & 11.42 & 11 & 8 & 25.81 & 1.09 \\
\hline University of Calgary, Canada & 30 & 762 & 25.40 & 13 & 12 & 40.00 & 2.43 \\
\hline University of British Columbia, Canada & 28 & 1020 & 36.43 & 12 & 8 & 28.57 & 3.49 \\
\hline University of Technology, Sydney, Australia & 27 & 200 & 7.41 & 8 & 13 & 48.15 & 0.71 \\
\hline Massachusetts General Hospital, USA & 27 & 533 & 19.74 & 13 & 10 & 37.04 & 1.89 \\
\hline Patanjali Research Foundation, Haridwar & 25 & 165 & 6.60 & 7 & 5 & 20.00 & 0.63 \\
\hline $\begin{array}{c}\text { Jawaharlal Institute of Postgraduate Medical Education and Research, } \\
\text { Pondicherry, India }\end{array}$ & 25 & 131 & 5.24 & 7 & 1 & 4.00 & 0.50 \\
\hline Boston University School of Medicine, USA & 25 & 832 & 33.28 & 13 & 5 & 20.00 & 3.19 \\
\hline University of Pittsburg, USA & 25 & 393 & 15.72 & 10 & 5 & 20.00 & 1.51 \\
\hline University of Exeter, U.K. & 24 & 179 & 7.46 & 7 & 12 & 50.00 & 0.71 \\
\hline Mayo Clinic, USA & 23 & 310 & 13.48 & 11 & 2 & 8.70 & 1.29 \\
\hline University of Texas M.D. Anderson Cancer Center, USA & 21 & 391 & 18.62 & 7 & 6 & 28.57 & 1.78 \\
\hline Total of 20 organizations & 858 & 14640 & 17.06 & 12.68 & 190 & 22.14 & 1.63 \\
\hline Total of World & 3966 & 41396 & 10.44 & & & & \\
\hline Share of top 20 organizations in World total output & 21.63 & 35.37 & & & & & \\
\hline
\end{tabular}

TP=Total Papers; TC=Total Citations; CPP=Citations Per Paper; HI=h-index; ICP=International Collaborative Papers; RCI=Relative Citation Index

Eleven authors registered publications output above the group average of 26.72: S. Telles (69 papers), H.R.Nagendra (52 papers), H. Cramer (48 papers), R. Lauche (36 papers), B.N.Gangadharr (35 papers), G. Dabos (34 papers), A. Balakrisna (31 papers), E. Ernst (31 papers), R. Nagarathna Swami (30 papers), N. Raghuram (28 papers) and S. Varambally (27 papers) during 2007-16.

Twelve authors registered impact above the group average of 15.55 citations per publication: R.B.Saper (42.86), H.R.Nagendra (23.62), G. Dabos (22.97), R. Nagarathna Swami (22.07), K.J.Sherman (21.52), K.E.Innis (20.93), J.Thirthalli (20.33), L. Cohen (19.07), A. Michalsen (17.05), N. RaghuramSwami (16.64) R. Lauche (16.25) and J.Langhorst (16.04) during 2007-16.

Eleven authors registered h-index above the group average of 10.36 of all authors: H.R.Nagendra (19), S. Telles (17), G. Dabos and H. Cramer (16 each), R. Nagarathna Swami, K.J.Sherman and R. Lauche (14 each), J. Langhorst, S.B.S. Khalsa, E. Ernst and B.N.Gangadharr (11 each) during 2007-16
Twelve authors contributed international collaborative publications share above the group average of $22.75 \%$ of all authors: P. Posadzki (52.94\%), N. RaghuramSwami (46.43), E. Ernst (41.94\%), S.B.S. Khalsa (39.13\%), R. Lauche (36.11\%), J. Langhorst (36.0\%), R.B. Saper (35.71\%), H. Cramer (35.42\%), G. Dabos(35.29\%), L. Cohen(33.33\%), H. Bhargav (33.33\%) and A. Michalsen (31.58\%) during 2007-16.

Thirteen authors registered the relative citation index above the group average (1.49) of all authors: R.B.Saper (4.11), H.R.Nagendra Swami (2.26), G. Dabos (2.20), R. Nagarathna Swami (2.11), K.J.Sherman (2.06), K.E. Innis(2.01), J. Thirthalli (1.95), L. Cohen (1.83), A. Michalsen (1.63), N. Raghuram (1.59), R. Lauche (1.56), J. Langhorst (1.54) and B H. Cramer (1.52) during 2007-16.

\section{Medium of Research Communication}

Of the total world output in the field of yoga research, $93.77 \%$ (3719) appeared in journals. The top 15 most productive journals, which published 27 to 128 papers each on yoga research, together accounted for $21.22 \%$ publication share (789 papers) in journals during 2007-16. Macro 
Table 6: Scientometric Profile of Top 25 Most Productive Authors in Global Yoga Research during 2007-16.

\begin{tabular}{|c|c|c|c|c|c|c|c|c|}
\hline $\begin{array}{l}\text { Name of the } \\
\text { Author }\end{array}$ & Affiliation of the Author & TP & TC & CPP & HI & ICP & \%ICP & $\mathrm{RCl}$ \\
\hline S. Telles & $\begin{array}{l}\text { ICMR Centre for Advanced Research, Yoga and Patanjali } \\
\text { Research Foundation, Bangalore, India }\end{array}$ & 69 & 686 & 9.94 & 17 & 10 & 14.49 & 0.95 \\
\hline H.R.Nagendra & Swami Vivekanda Yoga Anusandhan, Bangalore, India & 52 & 1228 & 23.62 & 19 & 4 & 7.69 & 2.26 \\
\hline H. Cramer & University of Duisburg-Essen, Germany & 48 & 762 & 15.88 & 16 & 17 & 35.42 & 1.52 \\
\hline R. Lauche & University of Duisburg-Essen, Germany & 36 & 585 & 16.25 & 14 & 13 & 36.11 & 1.56 \\
\hline B.N.Gangadharr & $\begin{array}{c}\text { National Institute of Mental Health and Neurosciences, } \\
\text { Bangalore, India }\end{array}$ & 35 & 442 & 12.63 & 11 & 4 & 11.43 & 1.21 \\
\hline G. Dabos & University of Duisburg-Essen, Germany & 34 & 781 & 22.97 & 16 & 12 & 35.29 & 2.20 \\
\hline A. Balakrisna & Patanjali Research Foundation, Haridwar & 31 & 212 & 6.84 & 8 & 1 & 3.23 & 0.66 \\
\hline E. Ernst & University of Exeter and Plymouth, U.K. & 31 & 405 & 13.06 & 11 & 13 & 41.94 & 1.25 \\
\hline R. Nagarathna & Swami Vivekanda Yoga Anusandhan, Bangalore, India & 30 & 662 & 22.07 & 14 & 4 & 13.33 & 2.11 \\
\hline S. Varambally & $\begin{array}{c}\text { National Institute of Mental Health and Neurosciences, } \\
\text { Bangalore, India }\end{array}$ & 27 & 341 & 12.63 & 10 & 2 & 7.41 & 1.21 \\
\hline N. Raghuram & Swami Vivekanda Yoga Anusandhan, Bangalore, India & 28 & 466 & 16.64 & 8 & 13 & 46.43 & 1.59 \\
\hline J.Langhorst & University of Duisburg-Essen, Germany & 25 & 401 & 16.04 & 11 & 9 & 36.00 & 1.54 \\
\hline K.J.Sherman & Group Health Research Institute, Seattle, USA & 25 & 538 & 21.52 & 14 & 3 & 12.00 & 2.06 \\
\hline S.B.S. Khalsa & Brigham and Women's Hospital, Boston, USA & 23 & 354 & 15.39 & 11 & 9 & 39.13 & 1.47 \\
\hline A. Michalsen & Charite-Universitat medizin, Berlin, Germany & 19 & 324 & 17.05 & 10 & 6 & 31.58 & 1.63 \\
\hline N. Singh & Patanjali Research Foundation, Haridwar & 19 & 135 & 7.11 & 6 & 1 & 5.26 & 0.68 \\
\hline H.Bhargav & $\begin{array}{l}\text { ICMR Centre for Advanced Research, Yoga and Patanjali } \\
\text { Research Foundation, Bangalore, India }\end{array}$ & 18 & 26 & 1.44 & 3 & 6 & 33.33 & 0.14 \\
\hline P. Posadzki & Plymouth University, Penisula School of Medicine, U.K. & 17 & 195 & 11.47 & 9 & 9 & 52.94 & 1.10 \\
\hline J.Adams & University of Queensland, Australia & 15 & 93 & 6.20 & 7 & 2 & 13.33 & 0.59 \\
\hline L. Cohen & University of Texas M.D. Anderson Cancer Centre, USA & 15 & 286 & 19.07 & 5 & 5 & 33.33 & 1.83 \\
\hline K.E.Innis & University of Virginia, Health Systems, VA, USA & 15 & 314 & 20.93 & 10 & 0 & 0.00 & 2.01 \\
\hline J.Thirthalli & $\begin{array}{c}\text { National Institute of Mental Health and Neurosciences, } \\
\text { Bangalore, India }\end{array}$ & 15 & 305 & 20.33 & 10 & 1 & 6.67 & 1.95 \\
\hline H.Lavretsky & University of California, California & 14 & 210 & 15.00 & 6 & 3 & 21.43 & 1.44 \\
\hline R.B.Saper & Boston Medical Centre, USA & 14 & 600 & 42.86 & 9 & 5 & 35.71 & 4.11 \\
\hline \multirow[t]{4}{*}{ A.B. Bhavanani } & $\begin{array}{c}\text { Jawaharlal Institute of Postgraduate Medical Education and } \\
\text { Research, Pondicherry, India }\end{array}$ & 13 & 38 & 2.92 & 4 & 0 & 0.00 & 0.28 \\
\hline & Total of 25 authors & 668 & 10389 & 15.55 & 10.36 & 152 & 22.75 & 1.49 \\
\hline & Total of World & 3966 & 41396 & 10.44 & & & & \\
\hline & Share of top 25 authors in World total output & 16.84 & 25.10 & & & & & \\
\hline
\end{tabular}

TP=Total Papers; TC=Total Citations; $\mathrm{CPP}=$ Citations Per Paper; HI=h-index; ICP=International Collaborative Papers; RCI=Relative Citation Index

level evaluation reveals that cumulative five-yearly publication share of top 15 most productive journals increased from $19.67 \%$ to $22.10 \%$ during the period between 2007-11 and 2012-16. The top ranking journals on yoga research were identified as: Journal of Alternate and Complementary Medicine (128 paper), followed by Evidence Based Complementary and Alternate Medicine (93 papers), Complementary Therapies in Medicine (64 papers), International Journal of Yoga Therapy (54 papers), etc. during 2007-16 (Table 7).

\section{Highly Cited Papers.}

Of the global output of 3966 papers on yoga research, 44 were identified as highly cited papers each receiving 101 to 1092 citations in 10 years during 2007-16. These 44 papers together cumulated 8304 citations, averaging to 188.72 citations per paper. Of the 44 highly cited papers,
11 resulted as contributions by authors affiliated to single stand-alone organizations (as non-collaborative papers) and 33 by authors affiliated to two or more collaborating organizations (25 national collaborative and 8 international collaborative). Among international collaborative papers, the largest participation was from USA (29 papers), followed by India (6 papers), U.K. (5 papers), Canada (4 papers), Australia, Germany, Italy and Netherlands (2 papers each), Switzerland, Singapore and Russia (1 paper each). Of the 44 highly cited papers, 22 were published as articles, 21 as review papers and 1 as book. These 44 highly cited papers were published in 35 journals, of which 5 appeared in Cochrane database of systematic reviews (Online), 2 papers each in Annals of Internal Medicine, Integrative Cancer Therapies, Journal of Alternative and Complementary Medicine and Pain and 1 paper each in 30 other journals, namely Acta Oncologicab, Acta Psychiatrica Scandinavica, Brain, Behavior, 
Table 7: Top 20 Most Productive Journals in Global Yoga Research during 2007-16.

\begin{tabular}{|c|c|c|c|c|}
\hline \multirow[t]{2}{*}{ S.No } & \multirow[t]{2}{*}{ Name of the Journal } & \multicolumn{3}{|c|}{ Number of Papers } \\
\hline & & 2007-11 & 2012-16 & 2007-16 \\
\hline 1 & Journal of Alternate and Complementary Medicine & 52 & 76 & 128 \\
\hline 2 & Evidence Based Complementary and Alternate Medicine & 21 & 72 & 93 \\
\hline 3 & Complementary Therapies in Medicine & 22 & 42 & 64 \\
\hline 4 & International Journal of Yoga Therapy & 17 & 37 & 54 \\
\hline 5 & BMC Complementary and Alternate Medicine & 14 & 38 & 52 \\
\hline 6 & Indian Journal of Physiology and Pharmacology & 22 & 27 & 49 \\
\hline 7 & Explore the Journal of Science and Healing & 23 & 24 & 47 \\
\hline 8 & Focus on Alternate and Complementary Therapies & 21 & 26 & 47 \\
\hline 9 & Complementary Therapies in Clinical Practice & 12 & 28 & 40 \\
\hline 10 & Journal of Ayurveda and Integrated Medicine & 16 & 24 & 40 \\
\hline 11 & Journal of Bodywork and Movement Therapies & 15 & 25 & 40 \\
\hline 12 & Journal of Clinical and Diagnostic Research & 6 & 32 & 38 \\
\hline 13 & Indian Journal of Psychiatry & 2 & 35 & 37 \\
\hline 14 & Integrated Cancer Therapies & 15 & 18 & 33 \\
\hline \multirow[t]{4}{*}{15} & Alternate Therapies in Health and Medicine & 8 & 19 & 27 \\
\hline & Total of 15 journals & 266 & 523 & 789 \\
\hline & Total global journal output & 1352 & 2367 & 3719 \\
\hline & Share of top 15 journals in global journal output & 19.67 & 22.10 & 21.22 \\
\hline
\end{tabular}

and Immunity, Circulation, Complementary Therapies in Medicine, Current Hypertension Reports, Evidence-based Complementary and Alternative Medicine, Evidence report/technology assessment, Hypertension, JAMA Journal of the American Medical Association, Journal of Abnormal Child Psychology, Journal of Clinical Oncology, Journal of Clinical Psychiatry, Journal of General Internal Medicine, Journal of Occupational Health Psychology, Journal of Psychiatric Practice Journal of the Society for Integrative Oncology, Maturitas, National Health Statistics Reports, Neuropsychopharmacology, Oncologist, Pain Medicine, Psychiatric Services, Psycho-Oncology, Psychotherapy, Science, Social Cognitive and Affective Neuroscience, Supportive Care in Cancer, The Lancet Oncology and Thorax.

To strengthen and encourage yoga research in the country, the government of India has established the Central Council for Research in Yoga and Naturopathy and has come up with programs to actively fund research projects on yoga studies. A few universities such as Swami Vivekananda Yoga Research Foundation, Bangalore and University of Patanjali at Hardwar have started bachelor, masters and Ph.D. degree programs on yoga and yoga research. Human Resource Development Ministry has constituted a committee to describe modalities for yoga education in Indian universities. Indian Council of Medical Research has established an advanced centre of research on yoga. Besides, many institutes of national importance, medical institutes such as AIIMS, PGIMER, NIHMHAS, etc. have set up yoga units to conduct research in this area. In addition, Ministry of Science and Technology, Govt. of India has started a programme to fund research projects on yoga and meditation. The basic themes of the program are: (i) effect of yoga and meditation on physical and mental health and (ii) the effect of yoga and meditation on body, brain and mind in terms of basic processes. In addition, Patanjali Research Foundation, Haridwar and Swami Vivekananda Yoga Research Foundation, Bangalore has created several programs on yoga to increase public awareness in the Indian subcontinent through the teachings of
Swami Ramdev. With these programs, India hopes to emerge as a leading country in yoga research within a few years.

\section{CONCLUSION}

This study provides a quantitative and qualitative description of the development of the research involving yoga research over a period of 10 years from 2007 to 2016 using publications data from the Scopus database.

The scientific literature related to yoga research registered a growth of $7.79 \%$ per annum, averaged to mere 10.44 citations per paper in 10 years period, which decreased from 18.41 to 5.87 from 2007-11 to 2012-16.

The USA is the top most productive country in the world in yoga research. India ranked $2^{\text {nd }}$ rank with $19.29 \%$ share followed by U.K. ( $3^{\text {rd }}$ rank with $6.61 \%$ share), Canada ( $4^{\text {th }}$ rank with $5.09 \%$ share), Australia ( $5^{\text {th }}$ rank with $4.54 \%$ share), Germany ( $6^{\text {th }}$ rank with $4.39 \%$ share), etc. The top 10 most productive countries in yoga research accounted for 83.74\% global publication and $96.67 \%$ global citation share during 2007-16. Amongst top 10 most productive countries, only five countries scored relative citation index above the world average i.e. more than 1 : Canada (1.81), USA (1.37), Germany (1.34), U.K. (1.31) and Italy (1.12) during 2007-16. The international collaborative share of top 10 countries in yoga research varied from $12.68 \%$ (India) to $42.59 \%$ (South Korea) during 2007-16. Medicine accounts for the largest share (78.67\%) in global yoga research, followed by several other subjects including psychology (9.56\%), biochemistry, genetics and molecular biology (9.53\%), health profession $(8.90 \%)$, nursing $(8.63 \%)$, social sciences (7.56\%), arts and humanities (6.98\%), pharmacology, toxicology and pharmaceutics (5.85\%) and neurosciences (5.09\%) during 2007-16. The research activity in medicine, social sciences and neurosciences registered increase, as against decline in health profession and nursing field during 
Gupta et al.: Yoga Research a Scientometric Assessment of Global Publications Output during 2007-16

period between 2007-11 and 2012-16. In terms of individual diseases, the largest yoga interventions were in depression (312 papers), stress (369 papers), anxiety (186 papers), breast cancer (138), neurologic disease (133), obesity (127), pain (125), anxiety disorders (119), chronic pain (104), stress (91), stress management (89), psychological stress (87), neoplasm (84), low back pain (79), insomnia (78), mental health (78), osteopathic medicine (77), mental stress (73), breast neoplasms (70), etc. The top 25 most productive organizations and authors together contributed $21.63 \%$ and $16.84 \%$ respectively global publication share and $35.37 \%$ and $25.10 \%$ respectively as their global citation share during 2007-16. Amongst the total journal output of 3719 papers, the top 15 journals contributed $21.22 \%$ share to the global journal output during 2007-16. Of the global yoga research output, the top 44 highly cited publications registered citations from 101 to 1092 and they together received 8304 citations, with 188.72 citations per paper. These 44 highly cited papers were published in 35 journals, 5 papers were published in Cochrane database of systematic reviews (Online), 2 papers each in Annals of Internal Medicine, Integrative Cancer Therapies, Journal of Alternative and Complementary Medicine and Pain and 1 paper each in other journals.

Conclusively, the North America (USA and Canada), Western (U.K., Germany and Italy) and Pacific countries (Australia) dominate yoga research both in quantitative and qualitative terms. Amongst developing countries, India ranks $2^{\text {nd }}$ top productive country in the world along with Brazil, South Korea and China $\left(7^{\text {th }}, 9^{\text {th }}\right.$ and $10^{\text {th }}$ rank) but with marginal contribution. To enable India perform better in qualitative terms, it is desirable that the stakeholders in the country give priority to yoga research as well as promote international collaboration across developed nations, in particular, with leading global yoga hubs located in the North America and western counties. In conclusion, yoga and meditation is still a young and upcoming field in alternative system of healing, growing at a moderate pace of $7.79 \%$. The challenge is how to speed up pace of research growth in yoga science.

\section{CONFLICT OF INTEREST}

The authors declare no conflict of interest.

\section{REFERENCES}

1. Benson H. The Relaxation Response. New York: Morrow, 1975.

2. Charmandari E, Tsigos C, Chrousos G. Endocrinology of the stress response. Annu Rev Physiol. 2005;67:259-84.

3. Cummings NA, Vanden Bos GR. The twenty years Kaiser-Permanente experience with psychotherapy and medical utilization: Implications for national health policy and national health insurance. Health Policy Q. 1981;1:159-75.

4. Kroenke K, Mangelsdorff AD. Common symptoms in ambulatory care - incidence, evaluation, therapy, and outcome. Am J Med. 1989;86(3):262-6.

5. Iyengar, BKS. Light on Yoga. New York: Schocken. 1995.

6. Kirkwood G, Rampes H, Tuffrey V, Richardson JK, Pilkington K. Yoga for anxiety: a systematic review of the research evidence. Br J Sports Med. 2005;39(12):884-91.

7. Pilkington K, Kirkwood G, Rampes H, Richardson J. Yoga for depression: the research evidence. J Affect Disord. 2005;89(1):13-24.

8. Cramer H, Lauche R, Langhorst JG, Dobos G. Yoga for depression: a systematic review and meta-analysis. Depress Anxiety. 2013;30(11):1068-83.

9. Lewith GT, Jonas WB, Walach DH, eds. Clinical Research in Complementary Therapies: Principles, Problems and Solutions. London: Churchill Livingston. 2012.

10. Riley $\mathrm{KE}$, Park CL. How does yoga reduce stress? A systematic review of mechanisms of change and guide to future inquiry. Health Psychol Rev April. 2015;15:1-18

11. Khalsa SB. Yoga as a therapeutic intervention: A bibliometric analysis of published research studies. Indian Journal of Physiology and Pharmacology. 2004;48(3):269-85.

12. Jeter PE, Slutsky J, Singh N, Khalsa SB. Yoga as a Therapeutic Intervention: A Bibliometric Analysis of Published Research Studies from 1967 to 2013. The Journal of Alternative and Complementary Medicine. 2015;21(10):586-92.

13. Field T. Yoga research review. Complementary Therapies in Clinical Practice. 2016;24:145-61. DOI: 10.1016/j.ctcp.2016.06.005.

14. Cramer H, Lauche R, Dobos G. Characteristics of randomized controlled trials of yoga: a bibliometric analysis. BMC Complementary and Alternative. 2014; 14(1):328. DOI: 10.1186/1472-6882-14-328

Cite this article: Gupta BM, Ahmed KKM, Dhawan SM, Gupta R. Yoga Research a Scientometric Assessment of Global Publications Output during 2007-16. Pharmacog J. 2018;10(3):394-402. 